\title{
H63D Syndrome: data and facts
}

\author{
Dr. Carolina Diamandis ${ }^{1}$ and Jacob S Adams ${ }^{1}$
}

${ }^{1}$ Affiliation not available

June 7,2021

\begin{abstract}
Ever since I co-founded the International H63D Research Consortium, I have always considered it my duty to pass on the most important knowledge about H63D syndrome to my colleagues in academia, research and applied medicine.

Before I leave the consortium for a new career step, there are still some data to be published, which my current colleagues will certainly work on in more detail at a later stage. After all, knowledge can save lives and prevent suffering. I will publish these data in the following, because they speak for themselves.
\end{abstract}

\section{Hosted file}

H63D syndrome data.pdf available at https://authorea.com/users/410930/articles/524862-h63dsyndrome-data-and-facts 